\title{
Keeping it Real: Vietnamese-English Pragmatic Representations in EFL Textbook
}

\author{
Tran Thi Mai Thi \\ Wenzao Ursuline University of Languages, Taiwan \\ wendytran1503@gmail.com \\ Aiden Yeh, Ph.D. \\ Wenzao Ursuline University of Languages, Taiwan \\ aidenyeh@gmail.com
}

DOI: https://doi.org/10.36892/ijlls.v2i1.105

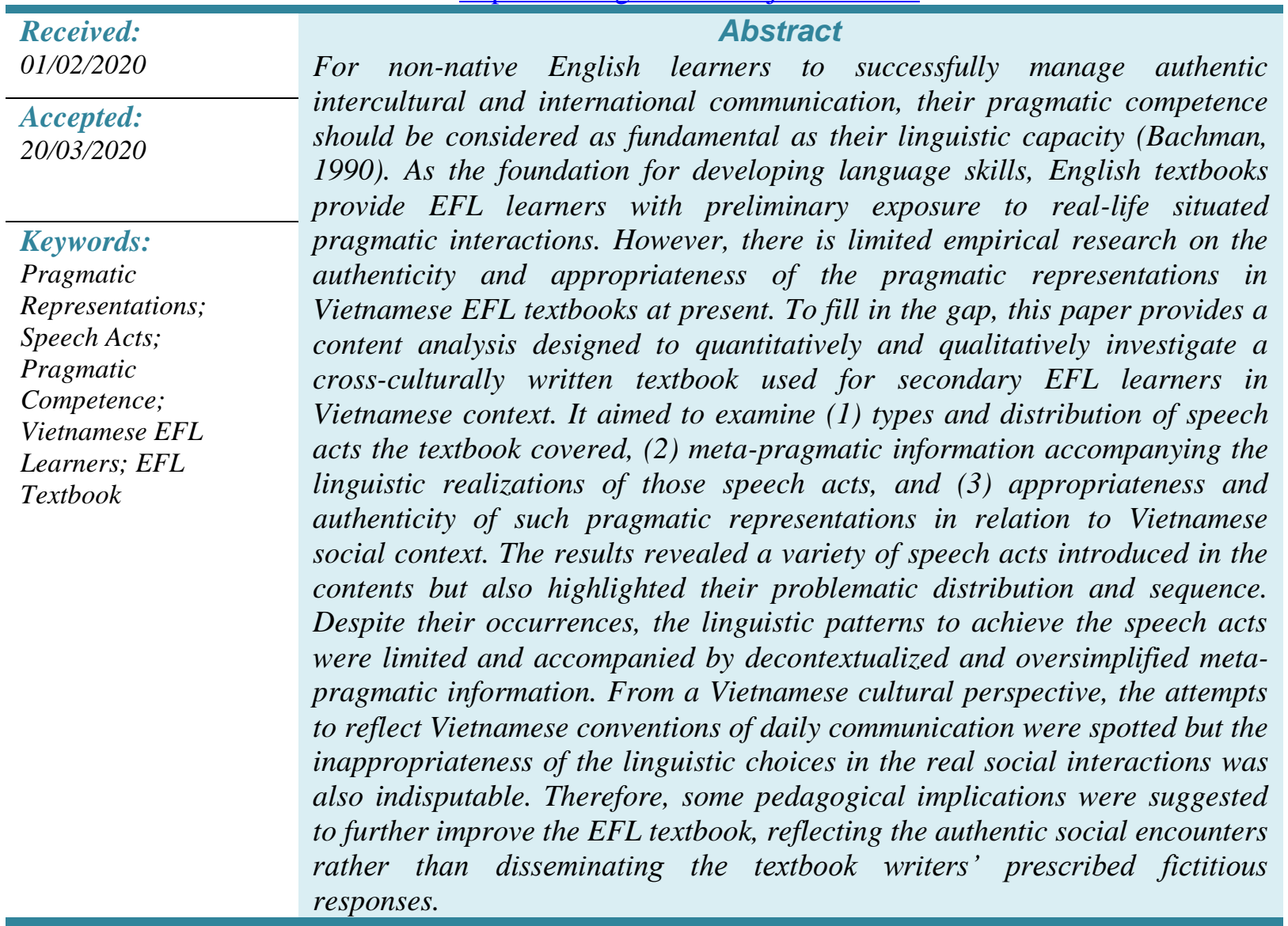

\section{INTRODUCTION}

In today's globalized world, English has become a significant tool to facilitate international contacts. Thus, instead of a wealth of theoretic linguistic compositions to understand English literature (Gulbinskienè \& Lasauskienè, 2014), English as a foreign language (EFL) teaching now prioritizes the authentic use of the language for intercultural and international encounters (Namaziandost, Hashemifardnia \& Hosseini, 2019; Ozverri, Osam \& Herrington, 2017). As proposed by Bachman (1990), learners should be both linguistically and pragmatically competent to manage realistic English-based conversations. Nonetheless, the grammatical development and capacities cannot necessarily predict their pragmatic competence (Bardovi-Harlig \& Dörnyei, 1998; Schauer, 2006). 
Being inextricably linked to its social meaning, native English pragmatic competence is a challenge for EFL learners given their disparate sociocultural frame and limited exposure to the target culture. The gap between classroom knowledge and real-world interactions also contributes to their lower awareness of pragmatic violation despite the strong lexicogrammatical repertoire in comparison with either ESL or native English speakers (BardoviHarlig \& Dörnyei, 1998; Jalilian \& Roohani, 2016; Ren \& Han, 2016; Schauer, 2006; Vellenga, 2004). Accordingly, to prepare EFL students as pragmatically competent nonnative English speakers, pragmatic knowledge should be instilled in their learning experience (Nguyen, 2011). In an effort to fulfil such aim, pedagogic strategies, teaching materials and classroom activities relevant to the acquisition of pragmatic knowledge are taken into consideration (McConachy \& Hata, 2013; Ren \& Han, 2016). As an important tool to convey knowledge and skills to students, textbooks are still valued as the backbone of EFL education (Lee, 2013; Nguyen, 2011). However, Berardo (2006) argued that artificial and unvaried input in EFL textbooks can result in students' failure to use English to meditate their social encounters. In other words, textbooks' realistic representations can be the precursor to make classroom-based students attuned to authentic English-based communication (Matsuda, 2002).

Research shows that the pragmatic dimensions in textbooks have not been well represented, especially when it comes to speech acts (Aksoyalp \& Toprak, 2015). ELT textbooks are considered unreliable and unrealistic sources of English pragmatic information, given the insufficient and unauthentic pragmatic input (Bardovi-Harlig, 2001; Diepenbroek \& Derwing, 2013; McConachy \& Hata, 2013; Ren \& Han, 2016). Besides, the inclination to underscore native English cultures (Matsuda, 2002; Tran \& Duong, 2015), the pragmalinguistic mistranslation from a specific language into English and the native English speakers' fictitious conversational samples (McConachy \& Hata, 2013; Wong, 2002) are typical concerns over English textbooks. Considering those problems, Vellenga (2004) concluded that the investigated EFL and ESL English textbooks were not reliable contributors to students' accumulation of pragmatic competence. Additionally, Matsuda (2002) postulated that non-native English speakers can use English language but still adopt their own social conventions of communication in international settings. Therefore, the noncontext and culture-deprived illustration of speech acts can also pave the way for prescriptive or stereotypical generalization of socio-pragmatic practice in a particular non-native English speaker population (McConachy \& Hata, 2013).

In Vietnam, the official ELT textbooks rolled out to public schools nationwide are chiefly authored by the Ministry of Education and Training (MOET), according to Hoang (2015). In fact, English pragmatics has received negligible academic attention compared to the grammar teaching in Vietnamese EFL education. Such propensity in part leads to Vietnamese EFL learners' frequent breakdown in practical social encounters despite their impressive performance in grammatical tests (Nguyen, 2011). In particular, Nguyen (2011) argued that the pragmatic knowledge in the contemporary official high school English textbooks used in Vietnam are of limited quantity and quality. However, little is revealed regarding the secondary or primary ELT textbooks, from which the majority of Vietnamese students gain initial exposure to the English-based communication.

Recently, with the open international policy and active integration into different regional and international organizations, English-based conversations with people from diverse linguistic and cultural backgrounds have become inevitable for Vietnamese young generation to venture into an increasingly globalized workplace. Hence, EFL education centering on the students' communicative capacities in authentic international interactions is fundamental in Vietnam (Chau \& Truong, 2019). The National Foreign Language 2020 Project implemented in 2008 attests to the significance of fostering the quality of EFL teaching practice in preparation for international and intercultural communicative 
requirements (Ding, 2016). In particular, the goal of EFL education is to develop the learners' communicative competence in EFL and the ability to confidently communicate for the daily needs of work and study in the integrated, multicultural and multilingual settings by 2020 (Hoang, 2015).

Adhering to the new national requirements, the local textbook writers have collaborated with the two leading international EFL and ESL textbook publishers, MacMillan Education and Pearson Education to a produce a ten-year English textbook series for Vietnamese EFL students from Grade 3 to Grade 12. The series are described as promoting the communicative competence, 'focusing on the ability to communicate successfully using the lexical, phonological and grammatical language systems of English in meaningful contexts' (Hoang, 2015 , p.7). Given such emphasis on practical use of language, the students' pragmatic awareness should be developed through the textbook contents. Now in use as pilot textbooks in a number of public schools, they are bound to replace the present locally produced English textbooks (Ding, 2016).

In such context, textbook evaluation can provide reliable measurement on the quality of the ones in use and the feasibility of future's improvement (Lee, 2013; Fong, DeWitt \& Leng, 2018). Such continuous process of collecting, analyzing and interpreting the data is considered profoundly important in the field of teaching English to students of other languages or TESOL (Genesee, 2001). Pragmatically speaking, reviewing the extent to which a language textbook reflects the nature of communication in specific sociocultural contexts is crucial to determine whether the material contributes to students' pragmatic appropriateness and awareness.

However, the teaching material cross-culturally produced by both native English speakers and non-native authors are yet to be carefully examined although they are supposed to serve as the main resource of reference to connect Vietnamese EFL learners with the naturalist fashion of English-based communication. Thus, to fill in the gap, this study set out to investigate the pragmatic representation in one of the cross-culturally written English textbooks for Vietnamese learners in secondary school level. It focused on the textbook's representations of English speech act strategies and Vietnamese cultural assumptions. In particular, the study scrutinized

(1) the range and distribution of the speech acts,

(2) the linguistic realizations and the meta-pragmatic information accompanied these speech acts, the authenticity and appropriateness of those linguistic realizations from Vietnamese-English pragmatic perspective

\section{LITERATURE REVIEW}

\section{English Pragmatic Competence}

Earlier noted as the 'knowledge of conditions and manner of appropriate use, in conformity with various purposes', pragmatic competence was essentially recognized as opposed to grammatical competence or 'the knowledge of form and meaning' (Chomsky, 1980, p.224). The term was later regarded as sociolinguistic competence, an indispensable component in the communicative competence model by Canale and Swain (1980). Likewise, Bachman (1990) postulated that to be communicatively competent in a second language, a combination of organizational or grammatical competence and pragmatic competence should be acquired.

Essentially, pragmatic competence is defined as the ability to produce and comprehend the social and contextual meaning of the target language (Bialystok, 1993; Garcia, 2004; Taguchi, 2015). In other words, within a particular social frame, a pragmatic 
conversationalist is able to both code their intentions and decode those of the other interlocutors with appropriate linguistic choices and to be well aware of the possible effect those verbal expressions have on the hearers (Crystal, 1997).

According to Leech (1983), pragmatic competence can be divided into two interrelated facets of pragma-linguistic and socio-pragmatic competence. In particular, the former means making suitable choices of lexico-syntactic resources or other pragmatic strategies including directness and indirectness, routines to perform, intensify or mitigate a communicative act (Rose \& Kasper, 2001). On the other hand, the socio-pragmatic competence is concerned with the ability to flexibly execute the speech-act strategies in accordance with the specific social and situational variables of a communicative encounter (Cenzo, 2007). Therefore, the language learners are expected to understand both linguistic and socio-cultural aspects of a language to appropriately use it in their authentic social interactions.

\section{Speech Act Theories}

First developed by Austin (1962), speech act is one significant branch of pragmatics. A speech act can be defined as the act of using language to execute an action such as asking questions, requesting or refusing (as cited in Namaziandost et al, 2019). Besides, speech acts help 'visualize the spoken words', making the utterances a channel to expressing feelings, emotions and thoughts (Muhartoyo, 2013, p. 952). In Austin's theory, speech acts comprise of three aspects namely locutionary act, illocutionary act, and perlocutionary act. These acts are explained as the literal meaning of the utterances, the speaker's underlying intentions, and the hearer's consequential reactions, respectively (Yule, 1966). Another controversial theory of speech acts developed by Searle (1976) proposed different speech act categorization concentrating on the group of indirect speech acts. In particular, speech acts can be classified into five groups of declaratives, directives, expressives, commissives, and representatives. Namaziandost et al. (2019) presented an in-depth breakdown of these five categories of speech acts in relation to their meanings, functions, and examples.

In this study, speech acts are coded and categorized based on the Austin's (1962) framework, labeling speech acts according to the specific intended functions such as compliments, thanks or requests. This particular method was once adopted in the studies by Vellenga (2004) and Nguyen (2011). In particular, Nguyen (2011) found 27 speech acts including 'giving opinions', 'responding to thanks', etc. over three textbooks. 21 categories of speech acts were recognized in the corpus of textbooks Vellenga (2004) studied, labelled as 'give advice', 'complain', 'order' etc.

\section{Intercultural Communication and Interlanguage Pragmatic Competence}

With the expansion of non-native English varieties (Kachru, 2000), rather than fostering the imitation of native English speakers, EFL and ESL education should emphasize teaching English-based communication between people from different national and cultural backgrounds (Matsuda, 2002). When people communicate interculturally, their inherent discrepancies in sociocultural conventions can arguably lead to either pragma-linguistic or socio-pragmatic failures (Fang, 2010; Nguyen, 2011; Thomas, 1983). On the one hand, the misunderstanding can stem from the non-native speaker's failure to use an appropriate linguistic realization in English to represent their original intention. This issue was reflected in a study by McConachy and Hata (2013) in which the author discussed the consequences of the inappropriate English translation from a Japanese speech act. On the other hand, conversational collapse can result from the gaps between the speakers' social and cultural frame of reference and that of the listeners. 
As Matsuda (2002) postulated, EFL learners can still be inclined to their own social assumptions while engaging in English-based communicative activities. Thus, besides those universal pragmatic strategies such as indirect intents and routine formulae, the speech act strategies usually adhere to the pragma-linguistic conventions of a specific culture (Kasper \& Schmidt, 1996). For example, compared to native English speakers' pragmatic apologies, research showed that those of EFL learners vary in terms of the intensity, quantity of explanation strategies as well as less frequent use of acknowledgement (Chang, 2011; Tatsuki, 2000). Likewise, Tran (2007) and Nhung (2014a) empirically proved that Vietnamese EFL learners rarely agree or appreciate in return to a compliment but frequently decide to downplay, disagree, explain or opt out. According to Kasper and Schmidt (1996), exclamatory questions to convey compliment was rarely used in Egyptian Arabic variety of English. In Taiwanese English, 'I think' is more of a signpost of contrasting opinions than softening their utterance (Bardovi-Harlig \& Hartford, 1996). Meanwhile, Aijmer (2004) confirmed that 'I don't know' is merely used to express uncertainty among L2 learners, while it can also indicate disagreement, filler and reduced commitment as for English natives.

Relatively speaking, pragmatic inadequateness causes intolerable intercultural communicative misunderstandings compared to grammatical errors. Not attuned to the authentic communicative conventions of the target culture, EFL learners' English-based communication in multicultural settings can be even more pragmatically vulnerable. Hence, the capacities of non-native English speakers to comprehend and produce appropriate English speech acts in specific cultural contexts is worth academic attention (Bardovi-Harlig, 1999; Chang, 2011; Dinh, 2016; Nguyen, 2011). In other words, EFL learners should be wellinformed about both the semantic meanings and the specific contextual and sociocultural factors that influence the realistic adaptation of English language.

\section{Necessary Factors of Pragmatic Representation in English Textbooks}

According to Kasper (1996), 'there must be pertinent input, the input has to be noticed, and learners need ample opportunities to develop a high level of control' in order to accumulate pragmatic knowledge (p. 148). Since textbooks are considered the preliminary language input for students' communicative activities both inside and outside the classroom, the demonstration and elaboration of pragmatic dimensions in English textbooks are pragmatically fundamental (Lee, 2013; Nguyen, 2011). Among all of the pragmatic aspects represented in ELT textbooks, speech acts account for most of research coverage, followed by conversational strategies, or the techniques to achieve the desired goals of communicative activities such as small talks, question tags or indirect questions (Diepenbroek \& Derwing, 2013; Kasper, 2006).

To effectively introduce the pragmatic components in textbooks, various factors should be taken into consideration. First, since pragmatic competence highlights the contextual meaning of language, contexts are the significant signpost for the learners to interpret and evaluate a pragmatically appropriate response for sociolinguistic interactions (Bergman \& Kasper, 1993; Han, 2014). Therefore, textbooks' conversational samples should be contextualized with enriched pragma-linguistic and cultural information so that learners can speak the language in a pragma-linguistically and socio-pragmatically acceptable manner (Vellenga, 2004; Nguyen, 2011). In other words, they should explicitly describe the sociocultural variables of specific lexico-grammatical items (Boxer \& Pickering, 1995; Taguchi, 2015). For example, how the linguistic forms convey varying degrees of politeness in different cultures should be elaborated to develop the pragmatic awareness of EFL learners in real-life encounters (Leech, 2014) Second, pragmatic topics and speech acts should be arranged in relation to their practical needs, levels of cognitive challenge and the learners' language proficiency to acquire them (Diepenbroek \& Derwing, 2013). Third, it is advisable 
that the speech act strategies should be manifested and learned in chains or in a conversational sequence, which reflects naturalist verbal responses instead of treating them as isolated items (Cohen, 2005). Additionally, relevant activities such as role-play and interactive discussion should be designed to help students practice and enhance pragmatic awareness (Vellenga, 2004).

Even when the pragmatic information in English textbooks are illustrated in specific intercultural dialogues, inauthentic linguistic choices to achieve communicative acts can possibly cause certain stereotypical and negative assumptions towards other cultures (McConachy \& Hata, 2013). Research from Chinese context argued that the interculturalpragmatic-deprived teaching materials and activities can contribute to the EFL learners' incapacity to pragmatically manage their authentic English-based intercultural contacts (Fang, 2010). Similarly, Nguyen (2008) studied the use of speech acts for criticizing among Vietnamese EFL learners and the Australian counterparts. The findings showed that insufficient instructions on the pragmatically acceptable English expressions to convey criticism reduced the group of non-native English speakers' sense of politeness when their feedback was meta-pragmatically scrutinized.

In turn, incorporating realistic spontaneous responses from real-life conversations or authentic corpus-based studies into the speech act representation in teaching materials is conducive to students' pragmatic acquisition and adaptation in practical social encounters (Bardovi-Harlig \& Mahan-Taylor, 2003). For example, the results from a contrastive study on English check-understanding expressions in naturally-occurring Hong Kong English conversations and in the ELT textbooks did provide some insightful implications to teach such speech strategies at school (Cheng \& Warren, 2007).

\section{Evaluation of Speech Acts in English textbooks}

Research has been concerned about the pragmatic knowledge illustrated in the ELT textbooks for either communicative purposes or integrated skills (Cheng \& Warren, 2007). According to Vellenga (2004) and Pérez-Hernández (2019), research on pragmatic components of ELT textbooks were mostly conducted to quantitatively evaluate the pragmatic input or assess the appropriateness of their linguistic realizations from nativeEnglish speakers' viewpoint. Some paid attention to the contribution of the relevant pragmatic instructions and tasks to the learners' pragmatic awareness (Vellenga, 2004). The differences in pragmatic development between EFL and ESL textbooks and between them and ELT textbooks used for native English speakers also captured academic interest (Schauer, 2006; Wyner \& Cohen, 2015). However, little has been done to examine the appropriateness of non-native English pragmatic information in the EFL and ESL textbooks in their respective social contexts.

In most English textbooks, speech acts usually receive marginalized attention, usually accompanied with no explicit definition (Aksoyalp \& Toprak, 2015; Diepenbroek \& Derwing, 2013). To assess their representation, speech acts are usually named as the specific functions they are supposed to serve in the texts, creating some exhaustive categories of 'advices' or 'apologies', etc. (examples can be seen in Nguyen, 2014; Vellenga, 2004). There are also various studies concerned with particular speech act strategies. For example, Aksoyalp and Toprak (2015) studied about apologies, complaints, suggestions. Jalilian and Roohani (2016) compared complaints and compliments in Iranian ELT textbooks while Inawati (2016) considered greetings in Indonesian EFL textbooks.

Overall, the downsides of ELT textbooks' pragmatic representation include both quantity and quality. In particular, McConachy and Hata (2013) and Nguyen (2011) empirically proved that the linguistic realizations of speech acts and other conversation strategies were underrepresented and usually prescribed as decontextualized phrases in most ELT textbooks. For example, the frequencies of speech acts to give compliments and 
complaints are high but their lexical-syntactic forms are restricted in the Iranian English course books (Alemi \& Irandoost, 2012). Han (1992) found that Korean EFL learners only use 'thank you' to respond to compliments because of the prescription they obtained from the Korean ELT textbooks. Vellenga (2004) found that the speech act of advising and suggesting are just achieved by using 'should' in the EFL textbooks examined. Furthermore, both the distribution and sequence of pragmatic topics are neither as well-organized nor universally consensual as those of grammatical representations (Diepenbroek \& Derwing, 2013). Vellenga (2004) and Nguyen (2011) reiterated that the occurrences and sequence of different types of speech acts covered in the English textbooks they investigated are incompatible with their complexity and necessity in real-world communication as well as the learners' language proficiency. By scrutinizing the case of indirect speech acts to express complaints presented in a groups of ELT textbooks used in Britain and the US from the native speakers' perspective, Boxer and Pickering (1995) argued that the textbooks did not reflect the authentic conversation strategies and sociolinguistic behaviors but the textbook writers' expected and prescribed responses. Such argument resonated with the results from Wong's (2002) comparison between real-life telephone conversations and those illustrated in ESL textbooks. The use of negative expressions to directly refuse a request or complain in the Vietnamese textbooks are considered rarely seen in practical interactions (Nguyen, 2011). While textbooks demonstrated different speech act strategies, meta-pragmatic information accompanying them remains discernibly insufficient or oversimplified (Peiying, 2007; Ren \& Han, 2016). McConachy and Hata (2013) noticed that the sociocultural variables influencing the linguistic choices and interpretation of a particular speech act are frequently neglected in ELT textbooks. This problem can arguably constrain the students' in-depth insights into English-based conversation strategies applied in specific interactive situations. Overall, to fulfil the previously mentioned gaps, this study not only focused on the pragma-linguistic aspect of English speech acts but also took social appropriateness of those linguistic realizations of the speech acts in Vietnamese context into consideration.

\section{MATERIALS AND METHODS}

A content analysis of a Grade 6 English language textbook in Vietnam was conducted with a view to evaluating its pragmatic representation. Not only did we identify the range and distribution of speech acts introduced in the textbook, we also examined the authenticity and appropriateness of the linguistic realizations of the speech acts in relation to Vietnamese cultural conventions, which were rarely touched in previous research studies.

\section{Materials}

The chosen textbook was a cross-cultural collaboration between Vietnamese local authors assigned by Vietnamese MOET and their native-English counterparts from Pearson Publishing House. As described by Hoang (2015), it was designed in accordance with the National Foreign Language Project 2020 and planned to be widely used for 12-year-old students at Grade 6, the first year in Vietnamese public secondary schools and achieving level A2 in Common European Framework of Reference (CEFR).

The textbook includes two volumes named Tập 1 (Volume 1) used for the first semester and Tạp 2 (Volume 2) used for the second semester. Each volume comprises of 6 units, claimed to endorse real-world relevance, communicative approach and cultural diversity. With regards to the textbook components, seven headings of Getting Started, A Closer Look 1, A Closer Look 2, Communication \& Culture, Skills 1 (Reading and Speaking), Skills 2 (Listening and Writing), and Looking Back make up a consistent outline for each unit. 
Analysis

Speech acts range and distribution

The number of speech acts in the textbook were first investigated. A speech act was counted once in a unit regardless of its occurrences within the content of that unit. Except for the reading passages, task instruction and Review sections, the counting covered sample dialogues and email exchanges, the lexical-syntactical summaries and assignments related to such linguistic structures. Each speech act was labelled as the purpose it aimed to perform, similar to how Nguyen (2011) coded and categorized the speech acts in her study. For example, 'hi' and 'hello' were categorized into group of 'open a conversation' and 'oh, sorry, we can't' into 'refuse suggestion'. The figures of speech acts in each unit in the two volumes were presented, conducive to examining the distribution of these speech acts in the textbook.

\section{Linguistic realizations, meta-pragmatic and contextual information}

The linguistic realizations to achieve the speech act strategies were examined quantitatively and qualitatively to assess their diversity and explicitness. First, the linguistic patterns to achieve the respective speech acts were listed and counted. Second, the explicitness of the meta-pragmatic and conversational contents accompanying the linguistic realizations were investigated to determine whether social appropriateness and authenticity was considered when these speech acts were represented. Finally, from interlanguage pragmatic perspective, the authors investigated whether these pragmatic representations reflected Vietnamese cultural conventions of communication.

\section{RESULTS AND DISCUSSION}

\section{Range and Distribution of Speech Acts}

Most speech acts in the textbook investigated were not explicitly defined, which resonated with Diepenbroek and Derwing (2013). Therefore, the categorization was based on the specific functions the texts fulfilled, as mentioned earlier. Overall, although the two volumes both cover a range of speech acts, Volume 2 used a noticeably smaller range and occurrence of speech acts. In particular, there were 91 instances of 27 different speech acts in Volume 1 and 73 across 25 speech act types in Volume 2 (Table 1). To ensure the credibility of the figures, the counting process was done independently by two researchers then checked again to ensure accuracy and credibility.

\section{Table 1. Occurrences of the Speech Acts in the Textbook}

\begin{tabular}{|c|c|c|c|c|c|}
\hline \multicolumn{3}{|c|}{ Volume 1} & \multicolumn{3}{|c|}{ Volume 2} \\
\hline Unit & $\begin{array}{l}\text { Number of } \\
\text { speech acts }\end{array}$ & $\begin{array}{c}\text { Total } \\
\text { occurrences }\end{array}$ & Unit & $\begin{array}{c}\text { Number of } \\
\text { Speech Acts }\end{array}$ & $\begin{array}{c}\text { Total } \\
\text { occurrences }\end{array}$ \\
\hline 1 & 16 & 91 & 7 & 14 & 73 \\
\hline 2 & 12 & & 8 & 14 & \\
\hline 3 & 16 & & 9 & 12 & \\
\hline 4 & 19 & & 10 & 11 & \\
\hline 5 & 16 & & 11 & 12 & \\
\hline 6 & 12 & & 12 & 10 & \\
\hline
\end{tabular}

Evidently, there is no discernible pattern of distribution of these speech acts. The overall occurrences fluctuate across 12 units, one third of which introduced 12 speech acts each. While the highest number of speech acts were found in Unit 4, nearly doubling the figure of Unit 12. 
These speech acts were of varying degrees of linguistic complication from simple formulaic greetings to open and close a conversation to some complicated speech acts like expressing requests, excuses, suggestions, agreement or disagreement (Table 2). This finding corroborates what Nguyen (2011) found in the speech act representations in EFL textbooks for Vietnamese upper secondary schools. Another similarity was the introduction of both recurring and non-recurring speech acts. Particularly, opening/closing a conversation, expressing agreement, exclamations, asking and giving opinions were most frequently represented speech acts. As stated by Nguyen (2011), such repetitive patterns allow students to constantly review the linguistic realizations of the speech acts. Meanwhile, a number of speech acts just appeared once or twice throughout the entire contents.

Table 2. The range of speech acts and the number of units covering them

\begin{tabular}{|c|c|c|c|c|}
\hline \multirow[t]{2}{*}{ No } & \multirow[t]{2}{*}{ Speech Acts } & \multicolumn{3}{|c|}{ Number of units } \\
\hline & & Vol 1 & Vol 2 & Total \\
\hline 1 & Opening a conversation & 6 & 5 & 11 \\
\hline 2 & Apologizing & 3 & 0 & 3 \\
\hline 3 & Accepting apology & 2 & 0 & 2 \\
\hline 4 & Requesting & 4 & 2 & 6 \\
\hline 5 & Accepting request & 3 & 2 & 5 \\
\hline 6 & Making introduction & 6 & 2 & 8 \\
\hline 7 & Making excuses & 4 & 1 & 4 \\
\hline 8 & Agreeing & 6 & 6 & 12 \\
\hline 9 & Complimenting & 5 & 4 & 8 \\
\hline 10 & Exclaiming & 6 & 5 & 10 \\
\hline 11 & Giving opinion & 6 & 6 & 12 \\
\hline 12 & Asking opinion & 6 & 6 & 12 \\
\hline 13 & Suggesting & 4 & 5 & 9 \\
\hline 14 & Accepting suggestion & 3 & 2 & 5 \\
\hline 15 & Refusing suggestion & 2 & 2 & 4 \\
\hline 16 & Thanking & 6 & 2 & 8 \\
\hline 17 & Accepting refusal & 1 & 0 & 1 \\
\hline 18 & Disagreeing & 1 & 2 & 3 \\
\hline 19 & Asking direction & 1 & 1 & 2 \\
\hline 20 & Giving instruction & 1 & 1 & 2 \\
\hline 21 & Responding to thanks & 1 & 0 & 1 \\
\hline 22 & Asking permission & 1 & 1 & 2 \\
\hline 23 & Advising & 1 & 0 & 1 \\
\hline 24 & Wishing & 2 & 2 & 4 \\
\hline 25 & Closing a conversation & 5 & 3 & 7 \\
\hline 26 & Checking understanding & 4 & 5 & 9 \\
\hline 27 & Predicting & 0 & 3 & 3 \\
\hline 28 & Complaining & 0 & 2 & 2 \\
\hline 29 & Congratulating & 0 & 1 & 1 \\
\hline 30 & Giving Order & 0 & 2 & 2 \\
\hline 31 & Promise & 1 & 0 & 1 \\
\hline
\end{tabular}

The sequence of the speech acts was apparently unsystematic, similar to the results from Ellis's (2008) and Nguyen's (2011) studies. In particular, the formulaic expression ' $m y$ pleasure' was presented only once and much later than other speech acts demanding complicated linguistic realizations and sophistication such as advising, suggesting, etc. Moreover, there was little systematic link between the linguistic complication of the speech 
acts and their frequencies. Generally speaking, the occurrence of face-threating speech acts was discernibly eclipsed by that of those conducive to establishing interlocutors' rapport. In particular, the groups of repeated speech acts included some basic ones such as showing thanks, exclamations while those complicated ones like refusing or asking for permission were not frequently addressed. Disagreement was much less common compared to the occurrence of agreement on a unit basis. Furthermore, compliments received noticeable attention while complaints were neglected in the textbook, which deviates from Alemi's (2012) findings. Although asking for directions, suggesting and refusing requests or suggestions are basic needs for daily communication, there was little room in the textbook concerned over such categories, opposed to what Diepenbroek and Derwing (2013) recommended.

\section{Linguistic realizations to achieve speech acts}

Quantitatively, the textbooks cover a variety of speech acts but the range of their linguistic realizations were not proportionately diverse. In particular, using modal verb should/shouldn't was the only strategy introduced to signal advising, which echoes Vellenga's (2004) finding. Meanwhile, no linguistic form to neither refuse a request nor accept a refusal was mentioned. Corroborating Cheng and Warren's (2007) findings, repeating information was the only strategy suggested for hearers to check understanding in the textbooks.

Overall, students were introduced with limited formulaic lexical-grammatical choices to convey their intentions. Such problem was confirmed in the other studies of EFL textbooks worldwide (Alemi \& Irandoost, 2012; Han, 1992; McConachy \& Hata, 2013; Vellenga, 2004).

Regarding the solidarity-strengthening speech acts such as opening conversations, showing compliments, thank-you and agreement, despite their overall occurrences, the range of formulaic expressions were limited. For example, greetings were recognized in almost every unit, however, ' $h i$ ' repeated 19 times while 'hello' and 'hi there' was mentioned once each. Moreover, the reciprocal responses and gratitude expressions after the perlocutionary acts of the requests were successfully decoded and executed by the hearers were rarely illustrated.

As for face-threatening speech acts such as complaints, disagreement or a suggestion refusal, a restricted number of lexico-grammatical realizations was recognized. Moreover, those speech acts were mainly achieved with direct expressions, taking for granted the realistic social and situational variables that probably withhold such negative responses. For example, to turn down another person's suggestions, a no was used immediately in Unit 4 while the non-mitigated criticism 'oh no...I don't like that! He's awful' was presented as the reaction to a suggestion. Meanwhile, the performative structure 'I do not agree with the idea that...' was suggested to express disagreement in Unit 12. In Vietnamese context, such direct negative refusals are usually avoided for posing a threat to the hearer's face (Nhung, 2014b). Evidently, those provocative expressions of intents differ from the universal prevalence of indirect intents in pragmatic speech act strategies (Kasper \& Schmidt, 1996). Such speech act representations were considered problematic and unrealistic as opposed to authentic social interactions (Nguyen, 2011).

\section{Meta-pragmatic information}

Although a number of speech acts were accompanied with some oversimplified explanation, all aiming to clarify the semantic or syntactic features rather than pragmatic meaning (Appendix). In other words, the metalinguistic information focused on the speakers' ability to structure their intents in English but not their pragmatic awareness. Also, the lexicogrammatical patterns such as modal verbs or conjunctions for specific communicative acts 
were mostly summarized in decontextualized boxes with no detail on the social or situational variables mentioned.

Some meta-pragmatic information was introduced much later after its first appearance in the content. For example, question using 'can' was introduced in unit 3 but the usage was expounded on in unit 12. Moreover, the pragmatic meanings of some samples were not even synonymous with the instructions. For example, 'must' was illustrated as 'an order' although the utterance 'You must come!' in Unit 9 (p.33) should have been inferred as a suggestion. Similarly, while imperatives were introduced to construe an order, 'come and watch it with $m e$ ' in Unit 8 was more of a suggestion than a command. In the following exchange, 'can' and 'will' did not simply meant 'an ability' and 'a possibility' as explained earlier:

(1) Duong: But you can learn! Will you come with me on Saturday? Mai: Well...OK.

In fact, they could be interpreted as imposing suggestions which resulted in the hearer's reluctant response.

Some linguistic expressions were regularly presented in sample dialogues without clarifying the practical usage. For example, using tag questions to check the speakers' understanding was not explicitly explained despite their occurrences in some sample conversations. The textbook also failed to elaborate the varying degree of politeness among the expressions for all speech act represented like greetings, thanks, requests and refusals although such clarification is critical to avoid misunderstanding or negative impression (Leech, 2014). For instance, in Unit 5, 'please' was frequently repeated in the examples, but no text exemplified its contribution to the politeness of requests. Likewise, besides its use to express possibility at the present mentioned in Unit 12, 'Can...., please?' was the only syntactic pattern to construe requests which was illustrated inUnit 3 while the politer alternative using "could" was completely neglected. In Vietnamese language whose verbs never conjugate according to tenses, both 'can' and 'could' are translated into 'có thế'. Moreover, although Vietnamese is flexible in its linguistic devices to code a pragmatic request such as using honorific terms and verbs to express the speakers' humility, pragmatic marker equivalent to 'please' is not socially conventional (Nguyen \& Ho, 2014). Therefore, Vietnamese EFL learners would not be aware of their differences in case of indirect requests if no explicit explanation is provided. Such limited awareness of a specific cultural assumption of their speech act used can lead to misunderstanding and stereotypes of their impoliteness in real-life intercultural communication (Nhung, 2014b).

Overall, the textbook contents downplayed any extra-linguistic factors and social meanings that affect the hearers' interpretation of their utterances. Such presentation attests to the unreliability of EFL textbooks as pragmatic teaching resources for their oversimplified link to the authentic use (Bardovi-Harlig, 2001; McConachy \& Hata, 2013). The oversimplification of illocutionary and perlocutionary speech acts and out-of-context grammatical guidance also resonate with the argument of Ren and Han (2016) and Peiying (2007). Thus, these pragmatic dimensions should be further explained by teachers or selfreflected by the students.

\section{Contextual information and authenticity of the sample conversation}

Most of the speech acts recognized were presented in conversations whose contexts were flexible and pertinent to daily life such as small talks with friends, video calls, class discussions, phone calls to invite somebody to a party or to order take-away food, interviews, etc. The communicative settings were also diverse so that conversations took place at supermarkets, at home, at school, during a holiday trips between people with various 
professional status and relationships and even nationalities. The interaction in writing skills were also varied covering email exchanges, blogs and postcards between friends, family members or students and teachers. The appropriateness in adopting speech acts in real-life situations and relationships between interlocutors were also touched though not frequently. In particular, in a "Making friends" game (Unit 1, p.11), the instruction was "Read and tick the questions you think are suitable to ask a new friend at school". Essentially, the authors did pay attention to encourage students to link the language they learn into practical daily life settings of communication. The attention on contexts of speech acts is confirmed as one significant components to teach speech acts in textbooks (Lee, 2013; Nguyen, 2011).

However, little information about the formality or interlocutors' relationship was available in the conversational samples to explain the pragmatic effects, corroborating Taguchi's (2015) argument. At the expense of authenticity, the conversations mainly aimed to expound on grammatical structures rather than their pragmatic meanings, revealing in the purpose of the instruction. Given the following examples,

Listen to part of the conversation from Getting started again. Then find and underline the present continuous form.

(2) Phong: Oh, someone is knocking at the door.

Phong's Mom: Hi Vy. You're early! Phong's having breakfast.

Vy: Hi, Mrs Nguyen. Oh dear, I'm sorry. I'm excited about our first day at school.

(3) Phong: But Tom is funny, too. Stupid but funny.

(Unit 1, p. 10)

Hung: Yes. Can you give me the newspaper in the desk?

Phong: Sure. Do you want to check the TV schedule?

Hung: Yes. Look...

(Unit 7, p. 6)

(4) Mai: Congratulations! How often do you do karate?

.....

Duong: But you can learn! Will you come with me on Saturday?

Mai: Well, ...OK.

Duong: Great! I'll meet you at the club at 10a.m.

Mai: Sure! Where is it? How do I get there?

Duong: It's Superfit Club, on Pham Van Dong Road. Take Bus 16 and get off at Hoa Binh Park. It's 15 minutes from your house.

Mai: OK. See you then.

Excuse me, where is the supermarket?

(Unit 8, p.16)

(Unit 4, p.25)

Presenting speech acts in a sequential context resonates with the strategy recommended by Cohen (2005). However, their movements do not necessarily adhere to the natural fashion of real-life conversations. In reality, the question Do you want to check the TV schedule? should be pragmatically understood as illocutionary acts of suggesting or offering. However, only yes in the response indicated that the question was just a closed question. Rather, a thank you should have been added if the writer had considered the authenticity of such social interaction.

In example (4), when Mai congratulated Duong on his winning, a response from the hearer should come before the speaker's follow-up question. Also, when a suggestion 'but you can learn!' was immediately followed by another suggested appointment, certain imposition was put on Mai. It was indicated in her hesitating acceptance. However, Duong's response was an exclamation (Great!). Arguably, the speaker expressed a complete ignorance of the other interlocutor's hesitation, which was not pragmatically appropriate in real life. Moreover, Mai quickly changed her feeling from redundancy to excitement when saying 'Sure!' even when she had no idea the location and direction to reach the venue. The consecutive questions of 'Where is it? How do I get there?' were also not really logical. In 
fact, Mai should have waited for the information about the location, then asked for direction in case she did not know. After Duong gave direction, the conversation closed abruptly although their on-field meeting just started.

Evidently, rather than instructing the learners to pragmatically interpret and adopt the speech acts in real-life interactions, the conversations that ignored the social and situational variables were manipulated as sentence-level demonstration of tenses, imperatives and $W h$ questions. In other words, the finding reiterates the argument that textbooks written with the author's prescribed speech acts cannot provide a reflection of authentic use of the language in social encounters (Bergman \& Kasper, 1993; Boxer \& Pickering, 1995; Cenzo, 2007; Han, 2014; Nguyen, 2011; Wong, 2002). In addition, such problematic speech act representation can be in part blame for the restricted politeness in authentic English-based communication of Vietnamese learners (Nguyen, 2008).

Given the tasks related to speech acts in the student-centered textbook, students were frequently asked to infer the meaning and visualize the contexts of the linguistic expressions based on specific conversations available. Such self-exploration adheres to the crucial condition of effective pragmatic teaching (Kasper, 1996). For example, students are asked to "find these expressions in the conversation. Check what they mean" regarding the phrases oh dear, come in, you'll see, sure! (Unit 1, p.7). In another instance, they have to 'brainstorm situations when people use these sentences. Then role play the situations with a partner' with an example provided 'you may need to spell your name when you order take-away pizza by phone' (Unit 5, p. 49). Such interactive activities as role play and discussion helpful to the students' awareness of realistic use of speech acts were also suggested by Vellenga (2004). Nonetheless, with no attention drawn to how the linguistic realizations are practically adapted in reality, the semantic meanings of the utterances were emphasized instead of the sociopragmatic appropriateness in specific interactions.

\section{The Vietnamese cultural conventions reflected in the speech act strategies}

To address the third research question, meta-pragmatic instruction and conversational contents were examined to determine whether they reflected the Vietnamese socio-cultural assumptions. Essentially, the textbook embraced a rich diversity of nations, illustrating their geographical and cultural facts. The sample conversations are among Vietnamese characters or between Vietnamese and international speakers in different settings of social interactions.

On the one hand, the speech act strategies in part revealed some features of Vietnamese social conventions (Table 3). In particular, in response to a considerable number of compliments, the Vietnamese habits of either explaining or changing the topics was demonstrated (Tran, 2007; Nhung, 2014a). Echoing Srichampa's (2009) study, honorifics and kinship terms to address senior interlocutors was evident in most sample dialogues. Moreover, I think was not utilized as a pragmatic marker of softening the tone as it is in native English (Bardovi-Harlig \& Hartford, 1996) but to express an opinion, equivalently to "tôi nghr̃" in Vietnamese language. Likewise, I don't know in the textbook merely indicated the speaker's inability to provide the information the speakers expected, which Aijmer (2004) considered pertinent to EFL population.

Table 3. Vietnamese social conventions revealed in the contents 


\begin{tabular}{|c|c|c|}
\hline $\begin{array}{l}\text { Address seniors kinship terms } \\
\text { and honorifics }\end{array}$ & $\begin{array}{l}\text { Hi Mrs Nguyen } \\
\text { Professor Lin, may I ask you a question? } \\
\text { Good morning Dr Alex }\end{array}$ & $\begin{array}{l}\text { Unit } 1, \text { p. } 6 \\
\text { Unit } 10, \text { p. } 41 \\
\text { Unit } 12, \text { p. } 58\end{array}$ \\
\hline State an opinion & I think.... & \\
\hline Opt out of compliments & $\begin{array}{l}\text { Phuc: Ha ha, Lucas is so friendly! } \\
\text { Duong: Can you pass me the biscuits, please? }\end{array}$ & Unit 3, p. 26 \\
\hline Explain to reply compliments & $\begin{array}{l}\text { A: Wow! You've got a new bike. } \\
\text { B: Yes. My mom bought it for me. She wants } \\
\text { me to keep fit. }\end{array}$ & Unit 8, p. 17 \\
\hline \multirow[t]{2}{*}{ Indicate the speaker's uncertainty } & $\begin{array}{l}\text { Oh, who's that? } \\
\text { I don't know. }\end{array}$ & Unit 3, p. 26 \\
\hline & $\begin{array}{l}\text { A: what is Lock Lomond? } \\
\text { B: I don't know. Do you know about it? }\end{array}$ & Unit 5, p. 56 \\
\hline State wishes in Lunar New Year & $\begin{array}{l}\text { I wish you a Happy New Year } \\
\text { I wish you good health and good luck } \\
\text { I wish you great success in your career }\end{array}$ & Unit 6, p. 67 \\
\hline \multirow[t]{2}{*}{$\begin{array}{l}\text { Using we in meta-linguistic } \\
\text { information }\end{array}$} & $\begin{array}{l}\text { We use can to talk about ability in the present } \\
\text { We use could to talk about ability in the past }\end{array}$ & \\
\hline & To express effects, we can use the structures ... & Unit 11, p.49 \\
\hline
\end{tabular}

As suggested by McConachy \& Hata (2013), to appropriately use a speech act in a specific culture, the materials should allow the interaction between them. Such strategy was adopted to introduce the speech act of wishing in the contexts of Vietnamese Lunar New Year. The culturally contextualized wishes reflected Vietnamese tradition. The unit also demonstrated the use of should/shouldn't while introducing Vietnamese cultural norms to bring good luck and avoid misfortune on New Year holiday. Moreover, a highly collectivist Vietnamese society was also reflected in some meta-pragmatic instructions using 'we'.

However, some certain speech acts in the textbook were inappropriate in Vietnamese context. Given a situation when a student asks the professor,

(1) Tom: So how much will the car cost?

Professor Lin: I don't know, but it won't be cheap. (Unit 10, p.41)

No honorific title to address a professor before raising a question is a sign of disrespect in Vietnamese cultural assumption (Nhung, 2014b). Besides, a direct response of 'I don't know' is not an expected answer from a Vietnamese teacher. The Vietnamese equivalent 'thầy không biết' in such case can connote the speakers' sense of anger or threatened face. Instead, a mitigated and indirect response like 'I'm not sure but...' (Thầy không chắc nhưng ....) is more advisable. In addition, 'honey' (Unit 2, p. 19) is not a typical term of endearment for a mom to address her children in Vietnamese culture. In this case, the native English term was intuitively prescribed for a conversation between two Vietnamese locals rather than reflecting what their culture usually speak.

Another problematic representation is recognized in a talk between a school girl and her friend's mother in example (2). According to Srichampa (2005), 'Greeting expression + Comments' is common greeting structure in Vietnamese culture. Therefore, in this case, 'You're early. Phong's having breakfast' could be understood as part of a greeting. However, given Vy's apology, the greeting must be interpreted as a complaint. Such reaction is arguably not natural in the interaction between two Vietnamese speakers. Also in the same dialogue, the hearer said thank you when being praised you look smart! Such acceptance of compliment is not prevalent in Vietnamese culture (Nguyen, 2011; Nhung, 2014a; Tran, 2007). In example (5), directly asking direction can indicate impoliteness in Vietnamese culture, where people prefer indirect questions such as 'Do you know the way to ...?' or 'Could you please show me how to go ...' 
To express exclamatory compliments, extremely positive adjectives such as 'wonderful', 'great', 'fantastic', 'lovely', 'cool' and 'amazing' were frequently used, being accompanied by the intensifiers of 'so' or 'very'. Those compliments were used in the sample conversations so that the speakers could maintain their turns in the conversations or praise the hearers' positive face and establish a rapport between the interlocutors. For example, 'You look smart!', 'You're very fit' 'Lucas is so friendly' were examples of rapport-establishing exclamatory compliments while 'That room looks so big, Nick', 'this is a great idea, Duong', 'this gym is great' were to open a conversation. However, utilizing extreme positive adjectives to praise is not common in realistic conversations in Vietnamese culture. In Unit 9 (p.26), 'what nice photos!' and 'what bad weather!' were introduced as ways to affectively express the speakers' feelings and start their turns in the conversation. The utterances can be respectively translated into Vietnamese as 'Những bức ảnh mới đẹp làm sao!' and 'thời tiết mới xấu làm sao!'. In fact, Vietnamese speakers hardly use such exclamatory questions in daily interactions. In other words, while Matsuda (2002) revealed the non-native speakers' tendency to retain their own socio-cultural communicative norms while speaking English, such exclamations hardly realistically reflected such inclination but more to provide the students with native English formulae to imitate and translate their original intentions.

\section{CONCLUSION}

The study examined the speech act representations in two volumes of a textbook for Grade 6 students in Vietnam which were cross-culturally produced by both local Vietnamese and native English textbook writers.

From the quantitative perspective, both volumes covered a variety of speech acts. Nonetheless, their distribution followed no specific sequence and the numbers of speech acts fluctuated across 12 units. Some speech acts found in the textbook were recognized in various units, however, the formulaic expressions to achieve the acts were not varied and presentation of linguistic realizations was inadequate.

Qualitatively, the pragmatic representations were marginalized compared to lexicosyntactic contents. Particularly, the speech act distribution and sequence were not grounded on the necessity or the linguistic sophistication. The frequencies of expressions to establish good rapport among the interlocutors also discernibly eclipsed those for face-threatening speech acts. Moreover, the directness for negative face threatening speech acts were still illustrated without any notice on potential negative perlocutionary acts from the hearers in realistic interactions.

As a communicative- and intercultural-oriented textbook, certain efforts were made to incorporate and diversify the daily settings of interactions and intercultural facts into the contents of the textbook. However, social and situational inauthenticity and inappropriateness are still inherent in the conversational samples of linguistic strategies to achieve the speech acts. The meta-pragmatic information was mostly oversimplified with little attention to pragmatic politeness and restricted socio-cultural adaptation. Noticeably, the fictitious linguistic strategies in responses to compliments and greetings and deprivation of honorific terms made some speech acts inappropriate and unnatural in the practical Vietnam-based settings. Overall, the dialogues were more to illustrate the sentence level of lexicogrammatical patterns than to elaborate the social and situational applications of the speech acts introduced.

This study only examined the concerns over speech act representation in one out of a series of EFL textbooks used in Vietnamese secondary schools. To grasp an in-depth evaluation of the pragmatic dimensions in the textbooks, we suggest that data for future studies can also cover other pragmatic components such as communicative strategies. 
Essentially, the aforementioned results reiterate the significant incorporation of pragmatic dimensions in English textbooks rather than the excessive attention on grammatical and lexical patterns. Moreover, to compensate for the discernible problematic pragmatic representations in the text, the role of teachers and learning activities should be noted. The textbook writers should also pay more attention to the authenticity and social dimensions of the conversation samples. In turn, the corpus-based research expounding on the real lifesituated pragmatic strategies should be developed and adapted in the textbook design. The linguistic strategies to achieve speech acts should reflect the naturalistic fashion of Vietnamese English pragmatic conventions rather than using the either local or native English-speaking authors' intuitive prescription.

\section{REFERENCES}

Aijmer, K. (2004). Pragmatic markers in spoken interlanguage. Nordic Journal of English Studies, 3(1), pp.173-190.

Aksoyalp, Y., \& Toprak, T. E. (2015). Incorporating pragmatic in English language teaching: To what extent do EFL course books address speech acts?. International Journal of Applied Linguistics \& English Literature, 4(2), 125-133.

Alemi, M., \& Irandoost, R. (2012). A textbook evaluation of speech acts: The case of English result series. IJALEE, 1(6), 199-209.

Austin, G. (1962). How to do things with words. Oxford: Oxford University Press

Bachman, L. (1990). Fundamental considerations in language testing. Oxford: Oxford University Press.

Bardovi-Harlig, K. \& Hartford, B. S. (1996). Input an institutional setting. Studies in Second Language Acquisition, 27, 171-188.

Bardovi-Harlig, K. \& Mahan-Taylor, R. (2003). Teaching Pragmatics. Washington DC: U.S. Department of State Office of English Language Programs.

Bardovi-Harlig, K. (1999). Exploring the interlanguage of interlanguage pragmatics: A research agenda for acquisitional pragmatics. Language Learning, 49(4), 677-713.

Bardovi-Harlig, K. (2001). Evaluating the empirical evidence: Grounds for instruction in pragmatics? In K. Rose \& G. Kasper (Eds.). Pragmatics in Language Teaching (pp. 1332). New York: Cambridge University Press.

Bardovi-Harlig, K., \& Dörnyei, Z. (1998). Do language learners recognize pragmatic violations? Pragmatic awareness in instructed L2 learning. TESOL Quarterly, 32(2), 233262.

Bialystok, E. (1993). Symbolic representation and attentional control in pragmatic competence. In Kasper, G., \& Blum-Kulka, S. (Eds.) Interlanguage pragmatics (pp. 43-57). Oxford: Oxford University Press

Boxer, D., \& Pickering, L. (1995). Problems in the presentation of speech acts in ELT materials: The case of complaints. ELT Journal, 49(1), 44-58

Canale, M. \& Swain, M. (1980). Theoretical bases of communicative approach to second language teaching and testing. Applied linguistics. 1, 1-47

Cenzo, J., 2007. The acquisition of pragmatic competence and multilingualism in foreign language contexts. In: Soler, E., Jorde, M. (Eds.), Intercultural language use and language learning. Springer, Netherlands, pp. 123-140. 
Chang, Y.-F. (2011). Interlanguage pragmatic development: The relation between pragmalinguistic competence and sociopragmatic competence. Language Sciences, 33(5), 786-798.

Chau, T. H. H., \& Truong, V. (2019). The integration of intercultural education into teaching English: What Vietnamese teachers do and say. International Journal of Instruction, 12(1), 441-456.

Cheng, W., \& Warren, M. (2007). Checking understandings: Comparing textbooks and a corpus of spoken English in Hong Kong. Language Awareness, 16(3), 190-207.

Chomsky, N. (1980). Rules and representations. New York: Columbia University Press.

Cohen, A. D. (2005). Strategies for learning and performing L2 speech acts. Intercultural Pragmatics, 2(3). doi:10.1515/iprg.2005.2.3.275

Crystal, D. (1997). A dictionary of linguistics and phonetics. 4th edition. Cambridge, MA: Blackwell

Diepenbroek, L. G. \& Derwing, T. M. (2013). To what extent do popular ESL textbooks incorporate oral fluency and pragmatic development? TESL Canada Journal, 30(7), 1-20.

Ding, T. N. (2016). Culture representation in locally produced English textbooks: A case study of Vietnam. Korean TESOL Journal, 12(1), 133-156

Ellis, R. (2008). The study of second language acquisition. Oxford: Oxford University Press.

Fang, J. (2010). A study on pragmatic failure in cross-cultural communication. Sino-US English Teaching, 7(12), 42-46.

Fong, F. C., De Witt, D., \& Leng, H. C. (2018). The analysis of cultural elements in Mandarins: A foreign language textbook from selected Malaysian public higher education institutions. Malaysian online Journal of Educational Sciences,6(1).

Garcia, P. (2004). Developmental differences in speech act recognition: A pragmatic awareness study. Language Awareness, 13(2), 96-115.

Genesee, F. (2001). Evaluation. In R. Carter, \& D. Nunan (Eds.), The Cambridge guide to teaching English to speakers of other languages (pp. 144-150). Cambridge: Cambridge University Press.

Gulbinskienè, D., \& Lasauskienè, R. (2014). Intercultural communicative competence (ICC) of EFL students at university level. Man \& the Word / Zmogus Ir Zodis, 16(3), 150-159

Han, C. (1992). A comparative study of compliment responses: Korean females in Korean interactions and in English interactions. Working Papers in Educational Linguistics 2, 1731.

Han, N. V. (2014). Contrast and critique of two approaches to discourse analysis: Conversation analysis and speech act theory. Advances in Language and Literary Studies, 5(4), 155162.

Hoang, V. V. (2015). The development of the ten-year English textbook series for Vietnamese schools under the national foreign language 2020 project: A cross-cultural collaborative experience. VNU Journal of Science: Foreign Studies, 31(3), 1-17

Inawati, I. (2016). The pragmatics of greetings reflected in the textbooks for teaching English as a foreign language in Indonesia. Ahmad Dahlan Journal of English Studies, 3(1), 2-10. 
Jalilian, M. \& Roohani, A. (2016). Evaluating speech acts in ELT textbooks: The case of compliments and complaints in the touchstone series. Research in English Language Pedagogy, 4(1), 101-114.

Kachru, B.B. (2000). Asia's Englishes and world Englishes. English Today,16(1), 17-22.

Kasper, G. (1996). Introduction: Pragmatics in SLA. Studies in Second Language Acquisition, $18,145-148$.

Kasper, G., \& Schmidt, R. (1996). Developmental issues in interlanguage pragmatics. Studies in Second Language Acquisition, 18(2), 149. doi:10.1017/s0272263100014868

Lee, S. M. (2013). The development of evaluation theories for foreign language textbooks. Journal of Pan-Pacific Association of Applied Linguistics, 17(2), 69-89.

Leech, G. (2014). The pragmatics of politeness. New York: Oxford University Press.

Matsuda, A. (2002). Representation of users and uses of English in beginning Japanese EFL textbooks. JALT Journal, 24(2), 182-215.

McConachy, T., \& Hata, K. (2013). Addressing textbook representations of pragmatics and culture. ELT Journal, 67(3), 294-301

Muhartoyo, K. K. (2013). Directive speech act in the movie "sleeping beauty". HUMANIORA, $4(2), 949-966$.

Namaziandost, E., Hashemifardnia, A., \& Hosseini, S. E. (2019). A survey of high school English textbooks in terms of using varying types of speech acts. Applied Linguistics Research Journal, 3(4), 24-32.

Nguyen, T. T. M. \& Ho, G. A. L. (2014). Acquisition of request modifiers in Vietnamese as a second language. JSEALS, 7, 31-51.

Nguyen, T. T. M. (2008). Criticizing in an L2: Pragmatic strategies used by Vietnamese EFL learners. Intercultural Pragmatics, 5(1), 41- 66.

Nguyen, T. T. M. (2011). Learning to communicate in a globalized world: To what extent do school textbooks facilitate the development of intercultural pragmatic competence? RELC Journal, 42(1), 17-30.

Ozverir, I., Osam, U. V., \& Herrington, J. (2017). Investigating the effects of authentic activities on foreign language learning: A design-based research approach. Journal of Educational Technology \& Society, 20(4), 261-274.

Peiying, J. 2007. Exploring pragmatic knowledge in college English textbooks. CELEA Journal 30(5), 109-119.

Pérez-Hernández, L. (2019). From research to the textbook: Assessing speech acts representation in course book series for students of English as an L2. Revista Española de Lingüística Aplicada/Spanish Journal of Applied Linguistics, 32(1), 248-276.

Nhung, P. T. H. (2014a). Strategies Employed by the Vietnamese to Respond to Compliments and the Influence of Compliment Receivers' Perception of the Compliment on Their Responses. International Journal of Linguistics, 6(2), 142.

Nhung, P. T. H. (2014b). How do the Vietnamese lose face? Understanding the concept of face through self-reported, face loss incidents. International Journal of Language and Linguistics, 2(3), 223-231.

Rose, K., Kasper, G., 2001. Pragmatics in language teaching. Camgridge: Cambridge University Press. 
Schauer, G. A. (2006). Pragmatic awareness in ESL and EFL Contexts: Contrast and development. Language Learning, 56(2), 269-318.

Searle, J. (1975). A Taxonomy of Illocutionary Acts. In Günderson, K. (Ed.) Language, Mind and Knowledge (pp. 344-369). Minneapolis: University of Minnesota Press.

Srichampa, S. (2005). Comparison of Greetings in the Vietnamese Dialects of Ha Noi and Ho Chi Minh City. The Mon-Khmer Studies Journal,35, 83-99.

Srichampa, S. (2009). Patterns of polite expressions in Vietnamese. Mon-Khmer Studies, 38, $117-147$.

Taguchi, N. 2015. 'Instructed pragmatics at a glance: where instructional studies were, are, and should be going'. Language Teaching 48(1), 1-50.

\section{AUTHORS'BIOS}

Tran Thi Mai Thi is a Vietnamese postgraduate student attending an MA in English program at Wenzao Ursuline University of Languages, Taiwan. Her research interests are English language teaching and Applied Linguistics.

Dr. Aiden Yeh is an Asst. Professor and Director of Academic Cooperation \& Exchange Section at Wenzao Ursuline University of Languages, Taiwan, where she also serves as Academic Adviser for Southeast Asian Studies Program. She has a PhD in Applied Linguistics (Birmingham University, UK) and MSc in ELT Management (Surrey University). 
APPENDIX

The meta-pragmatic information accompanying the speech acts

\begin{tabular}{|c|c|c|}
\hline Linguistic Realization & Explanation & Source \\
\hline $\begin{array}{l}\text { A: Can you ___ please? } \\
\text { B: Yes, sure. }\end{array}$ & making and responding to a request & Volume 1, p.27 \\
\hline $\begin{array}{l}\text { A: Would you like to } \\
\text { B: Yes, I'd love to./Oh sorry, I } \\
\text { can't. }\end{array}$ & $\begin{array}{l}\text { and 'making and responding to a } \\
\text { suggestion' as }\end{array}$ & \\
\hline Should/shouldn't & for advices & Volume 1 p 67 \\
\hline Will/won’t & for intentions & Volume 1 p 67 \\
\hline Must & for an order & Volume 2, p.19 \\
\hline Can & $\begin{array}{l}\text { we use can to talk about ability in the } \\
\text { present }\end{array}$ & Volume 12, p.59 \\
\hline Will & $\begin{array}{l}\text { for future, future possibility } \\
\text { we use will }+V \text { to talk about actions we } \\
\text { think are likely to happen in the future }\end{array}$ & Volume 2, p. 41 \\
\hline Might & $\begin{array}{l}\text { We use might }+\mathrm{V} \text { to talk about actions that } \\
\text { are possible in the future (We are not sure } \\
\text { that if they will happen or not) }\end{array}$ & Volume 2, p.42 \\
\hline Could & we use could to talk about ability in the past & Volume 12,p.60 \\
\hline Will be able to & we use be able to talk about future ability & Volume 2, p.61 \\
\hline And, but, so, because, although & $\begin{array}{l}\text { conjunctions are used to connect words and } \\
\text { ideas }\end{array}$ & Volume 2, p. 10 \\
\hline Wh-questions & $\begin{array}{l}\text { Each question is used for a specific piece of } \\
\text { information }\end{array}$ & Volume 2, Unit 7, p.9 \\
\hline $\begin{array}{l}\text { It's chewing gum } \\
\text { Chew it. } \\
\text { Don't swallow it. } \\
\text { Remember! } \\
\text { Positive: V } \\
\text { Negative: Don't + V. }\end{array}$ & $\begin{array}{l}\text { You use imperatives to tell somebody to do } \\
\text { something, or to give a direct order }\end{array}$ & \\
\hline $\begin{array}{l}\text { To make sb/sth do sth } \\
\text { To cause sth }\end{array}$ & To express effects & Unit 11, p. 49 \\
\hline $\begin{array}{l}\text { Firstly, secondly, next, then, } \\
\text { finally etc. }\end{array}$ & $\begin{array}{l}\text { Connectors are phrases or words used to link } \\
\text { one idea to another. There are many kinds of } \\
\text { connectors. Firstly, secondly, next, then, } \\
\text { finally etc. are used to show a sequence. }\end{array}$ & Unit 11, p.55 \\
\hline
\end{tabular}

